Nurses join firuity fundraiser

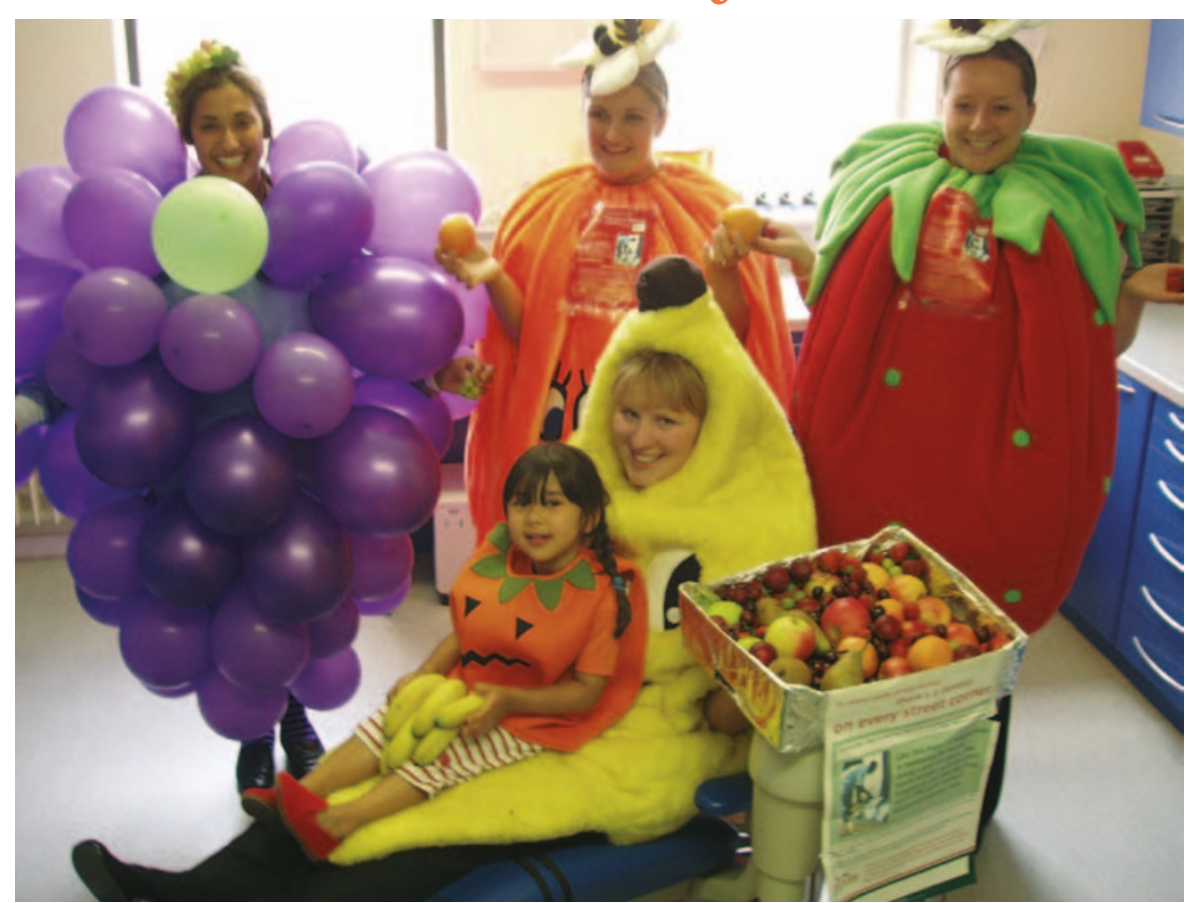

Amita Vezer (grapes), Deborah Lees (orange), Leanne Wilson (banana), Isabelle Vezer (pumpkin) and dental nurse Kathryn Barber (strawberry).

Dental nurses from the Cannon Street health centre in Oldham, donned fruit costumes as part of the national Dress up for Dentaid fundraiser in July.

Patients and staff donated money that will go towards improving oral health in the developing world.

Delphine Gratrix, clinical director for community dental services said: "I'm glad the team have been so enthusiastic about dressing up for charity. It is so important to support charities such as Dentaid because large parts of the world's population have very little access to even basic dental care. This means they are more likely to suffer from infection, illness, excruciating pain and even death."

Dentaid provides voluntary and clinical teams with equipment, education and prevention programmes.

\title{
Dental nurse pioneer retires
}

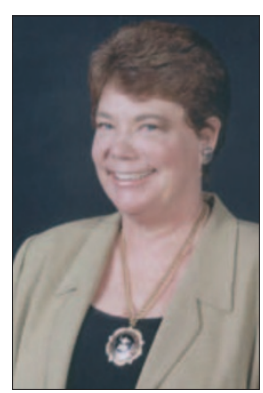

Diana Wincott, head of the centre for Dental Nursing Education and Training at Guy's, King's and St Thomas Dental Institute has retired after a career spanning 40 years.

A retirement party was held at Dulwich Art Gallery, London, where Professor Nairn Wilson presented her with a gift in honour of a lifetime dedicated to the dental nursing profession.
From her beginnings in general dental practice, Diana moved into dental nurse education where she was instrumental in developing and maintaining a leading role in dental nursing.

She held numerous roles within the Dental Nursing Association, including that of President, and was also the first dental nurse to chair the National Examining Board for Dental Nurses.

Diana was a member of numerous committees and an advisor to various dental organisations in the UK and overseas, and was awarded the MBE in 1998.

\section{PCIDs}

\section{win}

research

\section{awarcs}

Four professionals complementary to dentistry (PCD) were presented with Colgate PCD Research Awards at the annual meeting of the British Dental Association earlier this year.

The winners were dental therapist Jeanette Mooney (Manchester University Dental Hospital), senior lecturer for PCDs Margaret Ross (Edinburgh Postgraduate Dental Institute), dental hygienist Alison Lowe (Cardiff Dental Hospital) and dental hygienist Wenda Thomas (Dublin Dental Hospital).

"These awards are becoming increasingly recognised as an important forward looking initiative in helping to build and strengthen the academic base of the dental team. It is a great pleasure to encourage PCDs to embark on novel research of immediate clinical relevance", said Professor Nairn Wilson, chairman and acting director of the Oral Dental Research Trust (ODRT).

Jeanette Mooney and Margaret Ross were present at the BDA conference to receive their awards.

The awards, presented in partnership

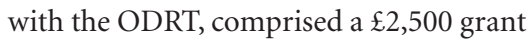
to support preventative care research.

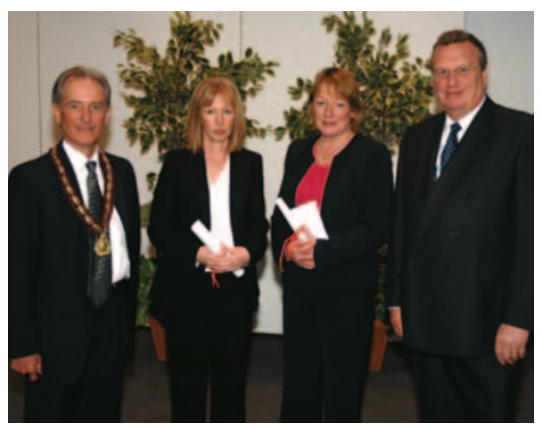

Left to right President of the British Dental Association John Craig, award winners Jeanette Mooney and Margaret Ross and Professor Nairn Wilson 